\title{
Cluster-mapping in China: the Empirical Evidence
}

\author{
Zhenming Sun \\ The O\&M Project Management, Sinoma SCC Project \\ Na Bi WU PO box 67105 \\ AL-HASSA 31928, Kingdom of Saudi Arabia \\ Tel: 96-6-532-076-880Ｅ-mail: masseyjamiesun@gmail.com
}

\begin{abstract}
A clear and precise exercise of cluster mapping may be viewed as the prerequisite for cluster identification and then for policy intervention designed to promote cluster development. In practice, there is no existing cluster mapping exercise widely accepted. However, there is no reason for stopping the endeavors to promote and standardize cluster mapping practice. This paper focuses on the review of cluster mapping exercises in China.
\end{abstract}

Keywords: Cluster, Cluster mapping, China, Empirical evidence

\section{Introduction}

For researchers and policy-makers, cluster identification is the initial step towards determining whether occurrence of business clusters is changing and in evaluating the possibility of endeavors to promote cluster formation (Perry, 2005). Unfortunately, so far, there is no agreed method to identify and map the distribution of business clusters. Even some strong advocators have to acknowledge that there are many handicaps to a kind of comprehensive and rigorous identification(Martin \& Sunley, 2003). Whatever researchers interpret and adapted the cluster definition in various ways, or they take various ways of information and various methods to identify clusters empirically, the outcomes that varying claims are made for the number of clusters exist and where they located (Martin \& Sunley, 2003). However, for example, if cluster applicants do not fit the categories identified in official statistics, it, thus, risks possible potentially large clusters being unrecognized. Such an example shown with a concentration of 54 domestic ceramic companies, encompassing more than 30,000 jobs in Beiliu City, Guangxi Province (Zhang, 2006). Official employment statistics allocated this sector among related industries. Once revealed, executives reportedly came together to work on issues of mutual interest, creating a stronger cluster. Consequently, to avoid misinforming executives about cluster status, measurement needs to be accuracy (Perry, 2005).

On the surface, a clear and comprehensive definition may be as a prerequisite for mapping clusters' frequency. However, all contemporary definitions for clusters ten to be short on explicit guidelines for cluster mapping (Perry, 2005). Porter (1998) defines cluster as "geographically proximate group of interconnected companies and associated institutions in a particular field, linked by commonalities and complementarities", which still offer seldom interpretation how to count clusters. Furthermore, a simplified concept, for example, " a regional cluster is an industrial cluster in which member firms are in close proximity to each other"(Enright, 1996). This simple concept poorly discuss on the issues how many activities constitutes a clusters and how close proximity must be, industrial categories and geographical boundaries can be adopted either to maximize or minimize the number of clusters counted (Perry, 2005).

Besides this, other four clustering-mapping strategies can be summarizes:

- One approach is to rely on " local experts", normally simply ask regional governmental agents $\mathrm{r}$ economic development agents to supply lists of regional clusters in their area which are then focused on more details (Martin \& Sunley, 2003).

- The development of cluster typologies may be considered as the second approach to cluster mapping.

- A third strategy for cluster mapping concentrates on the expected outcome of clusters. The main trend for individual studies of clusters to concentrates on successful stories is more likely to adopt outcome focus.

- The last mapping strategy is to use an input focus and seeks to identify clusters by the attributes that are expected to change firm behavior and performance. Generally, there are two basic attributes attached to clusters: one is 
connectedness, another is concentration.

Nevertheless, this is not the reason for stopping the endeavors to promote and standardize cluster mapping efforts. In the following section, this paper focuses on the review of cluster-mapping practices. Then, an evaluation of such practices is concluded.

\section{Cluster mapping in China}

There are really limited of cluster mapping concentration of Chinese manufacturing industries across the provinces or regions. Two cluster-mapping projects conducted in China, published in 2004 and 2005, share a stronger commitment to the conception of clusters as unique, local phenomena than Porter's cluster mapping project's emphasis on national industrial clusters (Ni, Hou, Jiang, \& Wang, 2005; Wang, Hou, \& Zhang, 2004). Both involve the use of location quotients (LQ). Furthermore, Wang, Hou \& Zhang (2004) specifically focus on Chinese auto manufacturing sector. So, with respect to such sector, direct comparison of the result may be possible due to the common base regions. Both studies conducted sought to identify geographically co-located activities whose interrelations reinforced their competitive advantage. In comparison to other countries such as French (Luxembourg, 2003) and the United Kingdom (Crouch \& Farrell, 2001) where the analysis is generally based on regional concentrations of industries defined at the five-digit SIC level, it defined at two or three-digit SIC level result in that Chinese national guoming jingji hangye fenglei yu daima (industrial identification and coding) system (GB/T4754-94) adapted two or three SIC. Therefore, it leads to that identification of clusters in China is problematic. In the study of $\mathrm{Ni}$ et al, for example, there are 47 cities where is the existence of transportation equipment manufacturing according the classification of GB/T $4754-94$. Based on the classification of manufacturing- transportation equipment manufacturing-ship floating device manufacturing, Dalian government classified into shipbuilding clusters. In comparison with Dalian, some regional governmental classified into of transportation equipment manufacturing clusters which includes tricycle manufacturing which should not classified into shipbuilding manufacturing sector, and it further weak the characteristics of clusters. Therefore, the denomination of clusters between regions based on the local requirement of development are various, which would seriously impact either the comparison of same types of clusters and distinguishing cluster or the cooperation across regions. Furthermore, such cluster mapping has two major limitations:

First, it assume is regions or nations are at the same level associated with labour productivity. One industry in some regions with a higher labour productivity, for example, will require less workforce than national average level of whole nation. In such situation, the coefficient of LQ might undervalue the clustering of this industry.

Second, the assumption is same in the terms of production and consumption model between local and national.

With the recognition of Porter's interpretation of clusters, Nevertheless, the analysis taken by Ni et al (2005) assumes clusters typically comprise linked activity from multiple industries. Hence, such efforts are given to seeking to build connections among industries. To the extent, they argue that business cluster has life cycle, and following the occurrence or closure of businesses, and the changes on local institutions, clusters evolve. Broadly, the tendency of cluster is further development. The development path can be divided into two stages (see the table 1). There is no difference from any cluster-mapping projects in other nations.

Another typical anecdotal cluster mapping project published in 2005 (Y. Zhu, 2005). A use of input-out data is to identify China business clusters. He suggests a method of descriptive approach to the analysis of industrial sectors. I $n$ particular, he lays out a means of using detailed information on national spatial industrial linkages that help identifying existing and potential clusters in China. Following the works of two researchers (Slater, 1977; D. Zhu, 2000),the functional linkages between individual industries are first estimated for Chinese economies. Such linkages can be shown to 'cluster' at the national level to present the linked re-aggregations of decimalized categories in the Standard Industrial Classification (SIC) system. When used in subsequent industrial sector analyses, the national clusters, in fact, has serve as templates for developing a strategic that is wholly distinct from the revealed through typical studies and data analyses that rely upon board the classification of GB/T 4754-94. The linkages are revealed by principal components factor analysis applied to the 1997 China input-output accounts. Interpretation of the consequence is guided by the objective to identify clusters based on separate industries with the tightest linkage to each other, allowing some cluster applicants to be interacted to other clusters as well. Specifically, Zhu (2000) identifies that there are 4 overall types, and 11 sub-types of business clusters in China. That is, business clusters is a system comprised by various industrial sectors. Such 11 sub-type business clusters comprise 96 industrial sectors, accounting for $78.2 \%$ with an output value of 16603.591 billion RMB and 83.1\% output value. By grouping those industrial sectors, that are most likely to interact with each other, both directly and indirectly, the cluster templates reveal relative specializations in various industries by exposing otherwise opaque extended functional chains. Hence, they are a valuable analytic tool for the design of economic development strategies that look forwards to exploiting or leveraging direct and indirect inter-sector linkages, or enhancing cross-regional cooperation. To some extent, guidance form such national analysis is judged better than an investigation of actual input-output linkages in the locality of interests. While local data reveal existing connectedness, they do not figure out gaps in functional linkages that may suggest potential development. 
Applied to one of recommendations of Zhu (2005), he argues that, for example, planting clusters and textile cluster seriously relying on condition of demand should the meet the existing demand, as well as creating new demand opportunities to promote China economic development. Similarly, applied to data from 1992 and 1997 provincial input-out tables, it shows that geographic agglomeration in industries with important comparative advantages, tightly supply linkages and high market potential (Batisse \& Poncet, 2003). They further claims that larger location quotients for industries experiencing high protection from interregional competition.

One more distinguish econometric contribution to the study of clusters are conducted by Chen (1996). In his study, he estimated sectoral value added as a function of capital, labour, and a function of factor multiplier that consists of five components, including agglomeration. Compared with machinery sector, the maximum impact of agglomeration on productivity in food sector is smaller (Chen, 1996). Following work of Chen (1996), Fan \& Scott (2003) proposes a framework similar to Chen's and on this basis seek to push the study of industrial concentration in China forward one more notch. Generally speaking, the procedure of their study can be divided into two phases (see table 2)

Applied to data from the second and the third national industrial censuses in 1980 and 1995, Wen (2004) examines the relocation and agglomeration after economic reform. His studies divided into two stages. Firstly, it looks 3-digit industrial locational Gini in 1995, aiming painting a picture of the spatial distribution of large and medium sized manufacturers to see whether their geographical locations reflect any economic rational. In the following stage, it concentrates on a historical comparison, based on the degrees of 2-digit all industrial enterprises concentration and attempts to analyses how Chinese manufacturing is re-located and concentrated. The results show that spatial location of Chinese manufacturing sectors have changed dramatically, with higher degree of geographical concentration for many industrial sectors and the relocation of some after 1978. That is say, the location of manufacturing sectors have shifted form an issue of war-preparedness between 1953-1978 to an economic preference after post-1978. To some extent, as a result of China economic reform, the relocation of industries reflects the industrial development policies taken in the period of economic period. In china, Labour mobility can facilitate both industrial agglomeration and industrial re-location. Industrial agglomeration can still be observed from 1980-1995, although the existing household registration system limits legal permanent migration form rural to urban areas and across regions. Furthermore, while numerous illegal migrants who can facilitate industrial concentration, substantial income inequality between regions, with a high average growth rate of real wage in eastern China. Wen (2004) claims costal regions such as Guandong, Jangsu, Shandong and Zhejiang have became home to many manufacturing industries result in preferential development policies. To some extent, Clams that Gini coefficients of 25 two-digit manufacturing industries in 1980, 1985 and 1995, and shows that the majority of such industries are highly concentrated, while chemical fibers, ferrous metal smelting and pressing, and non-ferrous metal smelting and pressing tend to disperse (Wen, 2004). In addition, Wen (2004) observe that the resource-based industries tend to be concentrated and many relatively footloose industries are agglomerated in costal China, while most of the industry sectors producing goods with higher transport costs are geographically dispersed. Wen (2004) also conclude both workforce and capital tend to flow from the interior to the costal provinces due to the reality that Chinese industrial agglomeration relies on both transaction agglomeration and production agglomeration with increasing return to scale in production.

A study conducted by (He, Wei, \& Xie, 2006) examine the spatial transformation of Chinese manufacturing sector between 1980-2003, and attempt to explore and explain degrees of geographical concentration with a particular certain to the impact of Chinese transition. They establish a panel dataset comprising of all two-digit manufacturing industries by provinces to examine the temporal tendency of geographical agglomeration of such industries from 1980-2003. Meanwhile, they focus on issues on investing the role of explanatory variables in changing the geographical concentration. Applied to data from Annual Report of Chinese Industrial Statistics from 1980-2003, they adopts Gini coefficient to examine 28 manufacturing industries in their study.

In the context of temporal trends of geographic concentration, the old industrial bases and interior provinces (Shanghai, Beijing, Sichuan, Hubei, liaoning, Jilin and Heilongjiang) in Mao's era appear a decrease of Gini coefficient of industrial gross output and value added. That is, since China economic reform, Costal provinces have gradually taken the advantages in attracting investment, improving technology, and expanding industries. Because the spatial pattern of industries of industries in inland provinces has been fairly stable since 1999, it implies that national strategy of Great Western Development launching in 1999 have reduced the regional inequality in such region. In China, due to a rapid growth in labour-intensive and light industries, provinces have represented less specialized since 1980, showing an overall pattern of convergence in provincial industrial structure. As the central government implemented more radical market reforms and open door policies in the early stage of 1990s, therefore, the overall provincial output specialization has been slowly increasing since mid-1990s. Moreover, in contrast to inner provinces, all industries in coastal provinces are more dispersed. In other words, it implies that costal areas are more economically developed and share similar locational advantages while the inner areas are still in the early stage of industrialization.

With respect to spatial pattern of industrial distribution, He et al (2006) claim that most highly concentrated industries 
are clustered in Guangdong, Jiangsu, Zhejiang, Shanghai and Shandong. For example, Guangdong, Zhejiang and Shanghai account for $74 \%$ market share in culture, education and sport goods sector; Jiangsu, Zhejiang, Shandong and Fujian account for $74 \%$ market share in chemical fibers sector. Owing to favourable policy treatment and preferential access to international market, globalized industries clustering in coastal region has emerged. For example, Guandong, Fujian and Zhejiang are responsible for $57 \%$ of value added in leather and fur products in 2003. Also, their analysis indicates that spatially clustering neighbouring provinces in some industries. For example, machinery and timber processing are clustering in Yangze River Delta. In addition, in China, industrial with large share foreign of foreign enterprises and export are move agglomerated than others, and analysis results also show that globalization forces have remarkably impacted the coastal shift of all industries. In 2005, a similar study is conducted by (Catin, Luo, \& Van Huffel, 2005). Based on the classification of Chinese industrial economic statistical yearbooks (30 groups of industries), they divide these 30 industries into two categories: 4 high-tech industries and other 26 industries (including two sub-categories -9 primary materials, energy and foodstuffs, and 17 labour intensive industries). They measure the degree of geographic concentration of an industry by calculating its Gini coefficient. The results are mixed. It shows that geographic concentration of activities differs across industries and regions (Costal /inland). Ultimately, they conclude that the distribution of activities in China is resulted in openness and industrialization.

The Gini index has been the most frequently used way of assessing the degree to which the regional distribution of one variable deviates from the regional deviates form the regional distribution of a 'neutral' yardstick. A choice of neutral comparison is able to impact the extent to which a separate activity is identified to be distributed unevenly. At the provincial level, a locality perspective indicates how the proportion of a locality's activity in a single industry compares with the provincial share of that industry and is assessed using some form of location quotient.

To identify clusters in Zhejiang Province, the overall concentration of products sales revenue was examined in conjunction with a measure to the industry's importance in individual localities(Liang et al., 2005). Applied to products sales revenue, Gini coefficients express the degree to which products sales revenue in an industry sector is unequally dispersed over localities. The localization of coefficient measures the level of industry concentration in a particular locality relative to the average sales revenues in the industry among all localities. To the extent a region with a high localization coefficient in an industrial sector that has a high Gini, that is, identifies a region demonstrating a especially high degree of concentration of an business activity that is unequally dispersed.

Generally speaking, based on the outcome of this cluster-mapping, Liang et al (2005) conclude that the degree of industry concentration in Zhejiang is high, and Zhejiang has made great progress in the programme of clusters-led growth. The 'high' must have a minimum Gini coefficient of 0.5. From the period between 1998-2003, the Gini coefficient in all industry sectors of Zhejiang is over 0.5. In term of spatial concentration, except timber processing and bamboo and rattan palm and grasses and other products manufacturing industry, Gini coefficient in each industry is higher than national average level, that is to say, there is a high degree of industry spatial concentration. More importantly, during the period from 1998-2003, the spatial concentration in Zhejiang manufacturing sector is gradually optimized. In Zhejiang, there are numerous examples of industries dominated by small firms that have high rates of spatial concentration. The majority of them are industries which is result in China economic reform after 1978. Apart from that, some of them are industries where firms are small due to a dependency on proximity to special-characteristic industrial districts. High-tech industry sector is comparatively higher concentrated.

Claims that cluster are significant tend to relate to regional natural elements and the changes of export situations. In comparison to other provinces, the impact of natural elements is weaker. However, there are still some clusters associated such cases. For example, the sales revenue of food processing sector accounts for $37.2 \%$ of the whole industry in the costal areas of Putuo District, Dinghai district and Beilun District. In addition, in some cases, claims appear to relate to business activities where the presence of a few leading firms in the region concerned can account for the concentration in Zhejiang.

Similarly, a cluster-mapping project is conducted in 2006(Zhang, 2006). Based on the data from Revenue Department, and the number of enterprises and employment in 2004 Shangxi Statistical Yearbook, Zhang(2006) uses two variables, namely, employment and the number of firms in particular industry with a three-digit SIC. Based on the result, Zhang (2006) claims that Coal-mining industry is with a highest localization ( $22.3 \%$ share of national output value). However, such industry sector comprise mainly of small firms, and most of them distributed dispersedly. In other words, it is not expected to represent clustering advantages. With respect to localization efficient of employment, claim appears to be distributed unevenly. Some industries have been developing with the formation of clustering. For example, the forging cluster in the county called Dingxiang comprise 683 firms with over 23000 employment, 30\% of total workforce in this area. Nevertheless, only a few industry sectors in Shangxi can be identified as cluster. For spatial concentration, they mainly distributed in big and small cities area and regions close to highways. 


\section{An evaluation of cluster-mapping projects}

Broadly speaking, cluster-mapping exercises are best designed as a two process (Perry, 2005). First of all, localities that potentially accommodate clusters should be identifies' secondly, profiles of potential clusters should be conducted to confirm that they qualify for inclusion and to determine how develop, if any, is made of the cluster by its prospective attendees. That is to say, such approach to cluster identification appears to point with some plausibility to a real connection between clusters, as well as economic development and growth. To some extent, the results is of particular interests result in concerns situations that are definitely distinguish from the use of individual case-study source found in the existing literature, which is mainly concentrated on developed high-income nations. With respect to the case of China, such analysis of Chinese industries sustains the argument that a positive relationship can be showed between clustering and economic growth. More importantly, industrial sectors and spaces are experiencing economic liberalization as those most prone to the formation of business clusters.

However, the extent, process and determinants of spatial distribution of industries in China still lack special attention (He et al., 2006). Nevertheless, limitations still exist and further study is expected.

(i) especially after access to WTO, however, the existing researches lack sufficient concerns about the impact of globalization and economic transition of the geographical patterns of industries (He et al., 2006).

(ii) Defects in Chinese industry Economy Statistical Yearbook. It only presents 20 manufacturing sectors by regions (provinces) after 1998, which leads to studies have to either stay on only 20 industry sectors or are confined to pre-1998. Also, it induces temporal compassion extremely difficult. In addition, due to a absence of coherent data, some studies are limited on the analyzing data under five year long, therefore, the temporal tendency of separate industry lacks a systemic investigation.;

(iii) An existence of theoretical argument on clusters and geographical agglomeration, hence, it is necessary to prove the theoretical literature associated with China and explore theoretical implication applied to Chinese situation.

\section{References}

Batisse, C. e., \& Poncet, S. (2003). Protectionism and industry localization in Chinese provinces. CERDI: Centre de Recherches et d'Etudes sur le D'eveloppement International. [Online] http://www.hiebs.hku.hk/events_updates/pdf/poncet.pdf.

Catin, M., Luo, X., \& Van Huffel, C. (2005). Openness, industrialization, and geographic concentration of activities in China. The World Bank in its series Policy Research Working Paper Series with number 3706.

Chen, Y. (1996). Impact of regional factors on productivity in China. Journal of Regional Science, 36(3), 417.

Crouch, C., \& Farrell, H. (2001). Great Britain: falling thourgh the holes in the network concept. In C. Crouch, P. L. Gales, C. Trogilia \& H. Voelzkow (Eds.), Local production system in Europe: rise or demise Oxford: Oxford University Press.

Enright M.J. (1996). Regional clusters and economic development: A research agenda, in Staber U., Schaefer N.V. and Sharma B., Business Networks: Prospects for Regional Development, DeGruyter, New York.

Fan, C.C. \& Scott, A. J. (2003). Industrial agglomeration and development: A survey of spatial economic issue in East Asia and a statistical analysis of Chinese regions. Economic Geography, 79, 295-319.

He, C., Wei, Y. D., \& Xie, X. (2006). Globalization, Institutional Change, and Industrial Location: Economic Transition and Industrial Concentration in China. Paper presented at the AAG Annual Meeting.

Liang, P., Chen, H., Lang, C., Lin, Y., Yuan, Y., \& He, T. (2005). Zhejiang chanyejiqun de jiben xianzhuang yiangxiang yinsu ji fazhan duice yanjiu. Hangzhou, Zhejiang Porvince.

Luxembourg. (2003). Trend Chart Policy Workshop“Innovative Hot Spots in Europe: Policies to promote trans-border clusters of creative activity” (Publication.: http://194.78.229.48/extranettrend/Upload/TCW14_policy_background_paper.pdf

Martin, R. and P. Sunley. (2003).Deconstructing clusters: chaotic concept or policy panacea? Journal of Economic Geography, 3: 5-35.

Ni, P., Hou, T., Jiang, M., \& Wang, C. (2005). Blue book of city competitiveness No.3. Beijing: Shehui Kexue Wenxian Chubanshe.

Porter, M. (1998). Clusters and the new economics of competition. Harvard Business Review, 76(6): 77-90.

Perry, M. (2005). Business Clusters: An International Perspective. Routledge, London.

Slater, P. B. (1977). The Determination of Groups of Functionally Integrated Industries in the United States Using a 
1967 Interindustry Flow Table. Empirical Economics, 2(1), 1-9.

Wang, J., Hou, F., \& Zhang, Y. (2004). Chanye Jiqun de shibie fangfa ji shizheng yanjiu . kexue xue yu kexuejishu guanli 11 .

Wen, M. (2004). Relocation and Agglomeration of Chinese Industry. Journal of Development Economics, 73, $329-347$.

Zhang, A. (2006). Shanxisheng zhongxiao qiyejiqun jujidu yanjiu. China industrial cluster, 31-41.

Zhu, D. (2000). Chanye jingjixue. Beijing Beijing ligong daxue chubanshe.

Zhu, Y. (2005). Zhongguo chanye jiqun fenxi.. Bejing Kexue jiaoyu chubanshe.

Table 1. Two development path of cluster presented by Ni et al (2005)

First Stage

Second Stage

\begin{tabular}{|c|c|}
\hline Germination & Renaissance \\
Development & or \\
Mature & Upgrading \\
Decline & Upgos \\
\hline
\end{tabular}

Table 2. The procedure of cluster-mapping project by Fan \& Scott (2003).

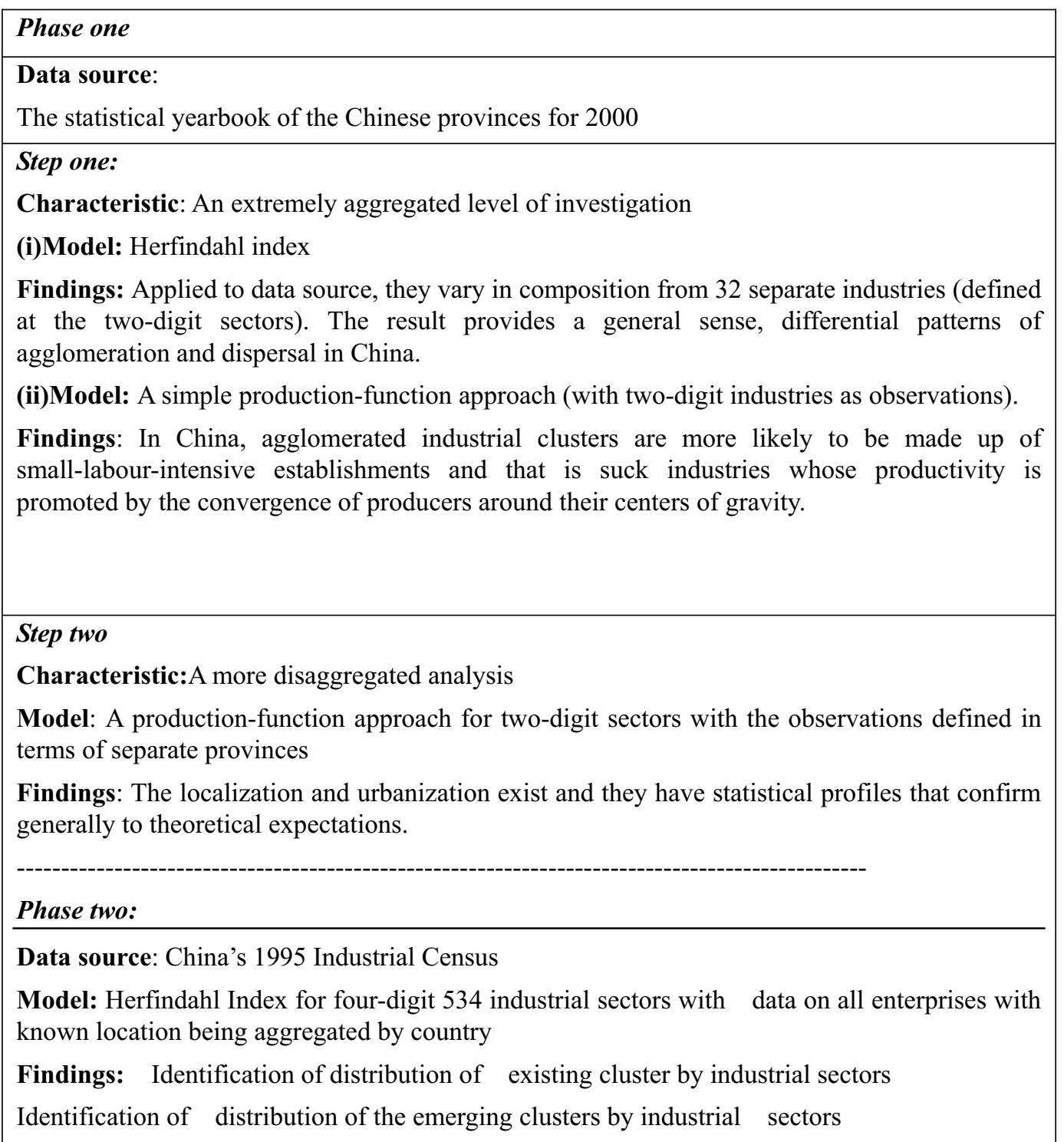

Source: Fan \& Scott (2003) 